\title{
A presença de alcalóides em espécies botânicas da Amazônia V. Determinação de cocaína em Erythroxylum através de cromatografia de alta pressão.(1)
}

\author{
A. 1. da Rocha $\left({ }^{(2}\right)$, A. I. Reis Luz $\left({ }^{3}\right)$, e F. Marx $\left({ }^{3}\right)$
}

\section{INTRODUÇÃO}

Mais de 200 espécies de Erythroxylum säo encontradas, na região tropical americana. Destas, duas espécies são particularmente cultivadas $E$. coca Lam e $E$. novogranatense (Mcrris) Hieron-, dadas as propriedades estimulantes, medicinais ou nutritivas que são atribuidas, pelos nativos, as suas folhas. E, também, para a obtenção de cocaína, seu principal componente biologicamente ativo, que é destinada, via de regra, ao comércio ilegal de entorpecentes.

\section{MATERIAL E MÉtodo}

Os métodos atuais mais freqüentes na determinação de cocaína utilizam cromatografia em fase gasosa (Aynilian et al., 1974) ou fragmentografia (Holmstedt, 1977 e 1978). Apre. sentamos, agora, um método mais rápido e mais fácil para ensaios qualitativos, baseado em cromatografia líquida de alta pressão, com fase reversa.

As amostras foram coletadas pela Polícia Federal em diversos pontos do Estado do Amazonas e identificadas pelo Dr. W. A. Rodrigues

(1) - Este trabaiho é financiado pelo Banco da Amazônia S.A.

(2) - Fundação Universidade do Amazonas, Manaus.

(3) - Instituto Nacional de Pesquisas da Amazônia, Manaus. 


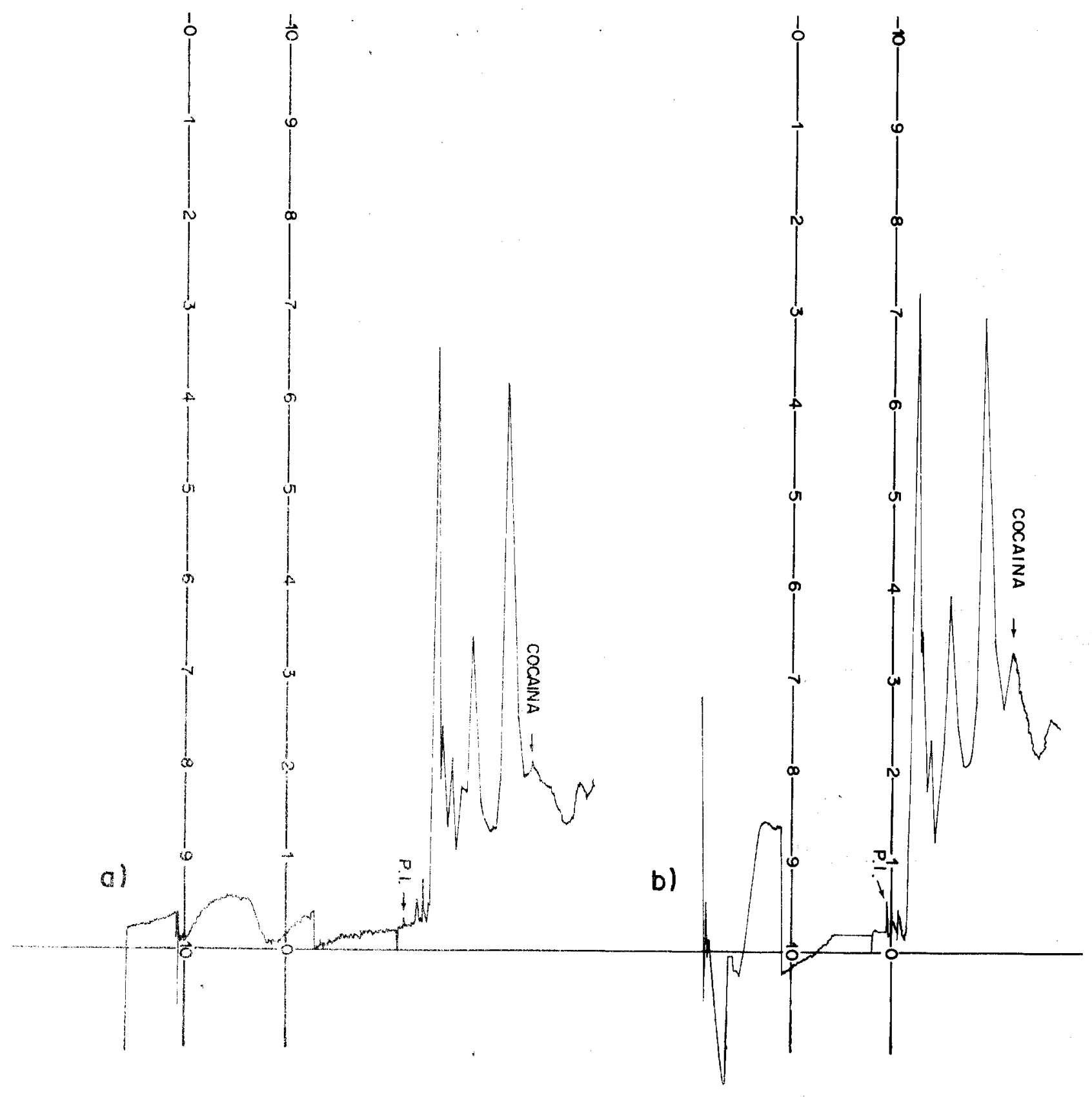

Fig. 1 - a) Cromatograma da amostra $n .^{\circ} 6$ de folhas de Erythroxylum $(30 \mu \mathrm{l})$; b) Cromatograma da amostra n. 6 de folhas de Erythroxylum $(30 \mu \mathrm{l})$ mais padrão de cocaína $(20 \mu \mathrm{l})$.

como originárias de Erythroxylum, por comparação, com exemplares pertencentes ao herbário do INPA, Manaus. 0 material para análise foi preparado por maceração de $100 \mathrm{mg}$ da amostra seca e pulverizada com $1 \mathrm{ml}$ de uma solução aquosa a $1 \%$ de ácido tartárico, durante cinco minutos seguida de filtração e lavagem com mais $1 \mathrm{ml}$ da solução tartárica (Rocha et al., 1968). O filtrado foi injetado após saturaçãc da coluna com cocaína em um aparelho de HPLC-Varian 8.500, munido de detector
UV-Vis-Varian Varichrom focado em $230 \mathrm{~nm} \mathrm{C}$ uma coluna de sílica gel ODS C18, $8 \mu \mathrm{m}, 0,4 \times$ $25 \mathrm{~cm}$ (LATEK), com o auxílio de um "loop injector" (LATEK, $100 \mu$ l). Como fase movei foi usada uma mistura composta de $68 \%$ de uma solução tampão de fosfato $0,05 \mathrm{M}(\mathrm{pH}$ 7) e $32 \%$ de - álcool metílico, a uma velocidade de $100 \mathrm{ml} /$ hora e pressão de $110 \mathrm{~atm}$., para um volume de injeção até $100 \mu \mathrm{l}$. Nestas condições, a cocaína eluiu 5 minutos após a injeção (ver gráfico). A coluna, após cada análise. foi 
lavada com $\mathrm{MeOH}(100 \%)$ durante 15 minutos. Conı padrão foi utilizada uma solução ccntendo : mg de cocaína dissolvida em $10 \mathrm{ml}$ de uma solução aquosa a $1 \%$ de ácido tartáricơ. O método apresent $\bar{c}_{i}$ uma sensibilidade satisfatória a partir da injeção de $20 \mu$ l de uma solução contendo $1 \mu \mathrm{g}$ de cocaína em $1 \mu$ l de solução.

\section{SUMMARY}

A method for a rapid determination of cocaine from Eriythroxylum using high-liquid pressure chromatography (HPLC) is described.

\section{REFERÊNCIAS BIBLIOGRÁFICAS}

AVNILIAN, G.H.; DUKE, J.A.; GENTNER, W.A.; FARNSWORTH, N.R.

1974 - Cocaine content of Erythroxylum species. J. Pharm. Sci, 63 (12), $1938-9$.
HOLMSTEDT, B.; JAATMAA, E.; LEANDER, K.; PLOWMAN, T.

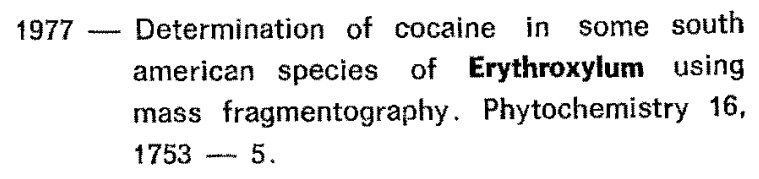

HOLMSTEDT, B.; LINDGREN, J.E.; RIVEIER, L.; PLOWMAN, T.

1978 - Cocaine in blood of coca chewers. Bot. Mus. Leafl. Harv. Univ. 26 (5), $199-201$.

ROCHA, A.I. da; SILVA, M.L.: MOURÃO, A.P,; CAVA, M.P.

1968 - A presença de Alcalóides em Espécies da Amazônia, Série Química, publicação $n$ : 12 - INPA - Manaus (AM).

(Aceito para publicação em $03 / 09 / 80$ ) 